\title{
DEVELOPMENT AND VALIDATION OF LIQUID CHROMATOGRAPHY COUPLED WITH TANDEM MASS SPECTROMETRY METHOD FOR ESTIMATION OF LENVATINIB IN HUMAN PLASMA
}

\author{
SRIKANTH I*, PRAMEELA RANI A \\ Department of Pharmaceutical Sciences, University College of Pharmaceutical Sciences, Acharya Nagarjuna University, Guntur - 522 510, \\ Andhra Pradesh, India. Email: chrissrikant@gmail.com
}

Received: 05 March 2017, Revised and Accepted: 13 April 2017

\section{ABSTRACT}

Objective: This study was to develop and validate a liquid chromatography-tandem mass spectrometry (LC-MS/MS) for the quantification of lenvatinib (LT) in human plasma.

Methods: A simple, sensitive and specific LC-MS/MS method was developed for quantification of LT in human plasma using LTD4 as internal standard (IS). The analytical method consists of liquid-liquid extraction of plasma sample followed by the determination of LT by a LC-MS/MS. The analyte was separated on a Zorbax Eclipse XDB-C18 $(150 \times 4.6 \mathrm{~mm}, 5 \mu)$ column with an isocratic mobile phase of acetontrile:0.1\% formic acid $(80: 20 \mathrm{v} / \mathrm{v})$ at a flow rate of $0.6 \mathrm{~mL} /$ minutes. The protonated ions were formed by a turbolon spray in a positive mode were used to detect analyte and IS. The MS/MS detection was made by monitoring the fragmentation of $\mathrm{m} / \mathrm{z} 427.10 \rightarrow 370.10$ for LT and $\mathrm{m} / \mathrm{z} 430.30 \rightarrow 370.10$ for IS on a MS.

Result: The method was validated with the correlation coefficients of $\left(\mathrm{r}^{2}\right) \geq 0.995$ over a linear concentration range of $10.20-501.60$ pg/mL. This method demonstrated intra- and inter-day precision within 1.06-2.42\% and 0.03-0.55\% and accuracy within 95.64-100.08\% and 97.16-100.07\%.

Conclusion: This method is suitable and convenient to pharmacokinetics and bioavailability studies for estimation of LT in biological samples by LC-MS/MS

Keywords: Lenvatinib, Validation, Analysis, Liquid chromatography-tandem mass spectrometry.

(C) 2017 The Authors. Published by Innovare Academic Sciences Pvt Ltd. This is an open access article under the CC BY license (http://creativecommons. org/licenses/by/4. 0/) DOI: http://dx.doi.org/10.22159/ajpcr.2017.v10i7.18287

\section{INTRODUCTION}

Lenvatinib (LT) is a multiple receptor tyrosine kinase inhibitor indicated for the treatment of thyroid cancer. LT mesylate is chemically known as 4-[3-chloro-4-(cyclopropyl carbamoyl amino) phenoxy]7-methoxyquinoline-6-carboxamide; methane sulfonic acid (Fig. 1). The chemical formula of LT is $\mathrm{C}_{21} \mathrm{H}_{19} \mathrm{ClN}_{4} \mathrm{O}_{4}$, and its molecular weight is 426.853 [1-8]

Literature review reveals that very few analytical methods have been reported for the determination of LT which includes high-performance liquid chromatography (HPLC) [9], LC-mass spectroscopy (MS), [10,11] and pharmacokinetics studies [12-15]

From the literature review, it was concluded that the reported methods used the lack of deuterated internal standard (IS) using HPLC-ESI-MS/MS methods. There is no method reported for estimation of LT using deuterated IS in biological samples [16].

The main goal of this study is to develop and validate the novel simple, sensitive, selective, rapid, rugged, and reproducible analytical method for quantitative determination of LT in human plasma by HPLC-ESI-MS/MS.

\section{MATERIALS AND METHODS}

\section{Instrumentation}

The Agilent 1200 Series HPLC system (Agilent Technologies, Waldbronn, Germany) connected to the API 4000 triple quadrupole instrument (ABI-SCIEX, Toronto, Canada) with turbo electrospray interface in positive ionization mode was used. Data processing was performed on Analyst 1.4.1 software package (SCIEX).

Reagents/materials

LT was obtained from Cadila Pharmaceuticals, India. Lenvatinib-D4 (LTD4) was procured from ClearSynth, India. Water (HPLC Grade), formic acid (analytical grade) was purchased from Merck, Mumbai, India. Acetonitrile (HPLC Grade), ethyl acetate, and dichloromethane (HPLC grade) were obtained from J.T. Baker, USA. Human plasma was procured from Navjeevan Blood Bank, Hyderabad. Milli-Q water was taken from the in-house Milli-Q system.

\section{Detection}

Detection was done by turbolon spray (API) positive mode with unit resolution. Mass transitions were obtained from $427.10 \rightarrow 370.10$ for LT and $\mathrm{m} / \mathrm{z} 430.30 \rightarrow 370.10$ for LTD 4 .

\section{Chromatographic conditions}

Chromatographic separation was performed using an Xbridge Zorbax Eclipse XDB-C18 $(150 \times 4.6 \mathrm{~mm}, 5 \mu)$ at a temperature of $40^{\circ} \mathrm{C}$. The mobile phase was composed of acetontrile:0.1\% formic acid (80:20, v/v) at a flow rate of $0.6 \mathrm{~mL} /$ minutes. Deuterated LTD4 (IS) was used as the appropriate IS in terms of chromatography and extractability. LT and LTD4 were eluted at 4.53 minutes, approximately, with a total runtime of 8 minutes for each sample.

\section{Preparation of standards and quality control (QC) samples} Standard stock solutions of LT $(10.0 \mathrm{mg} / \mathrm{mL})$ and LTD $4(10.0 \mathrm{mg} / \mathrm{mL})$ were prepared in acetonitrile. The IS spiking solution $(100.0 \mathrm{pg} / \mathrm{mL})$ was prepared in mobile phase solution acetonitrile: $0.1 \%$ formic acid $(80: 20, v / v)$ from LTD4 stock solution. Standard stock solutions and IS spiking solutions were stored in refrigerator conditions of $2-8^{\circ} \mathrm{C}$ until analysis. Standard stock solutions of LT $(10.0 \mathrm{mg} / \mathrm{mL})$ were added to drug-free screened human plasma to obtain concentration levels of 10.2, 20.1, 35.1, 70.2, 100.3, 200.6, 301.2, 401.3, and $501.6 \mathrm{pg} / \mathrm{mL}$ for analytical standards, and 10.2 (lower limit of quantification [LLOQ]), 30.1 (lower QC [LQC]), 250.1 (middle QC [MQC]) and $461.6 \mathrm{pg} / \mathrm{mL}$ (high QC [HQC]) for QC standards, and stored in the freezer at $30^{\circ} \mathrm{C}$ until analysis. The aqueous standards were prepared in a mobile phase solution acetonitrile: $0.1 \%$ formic 


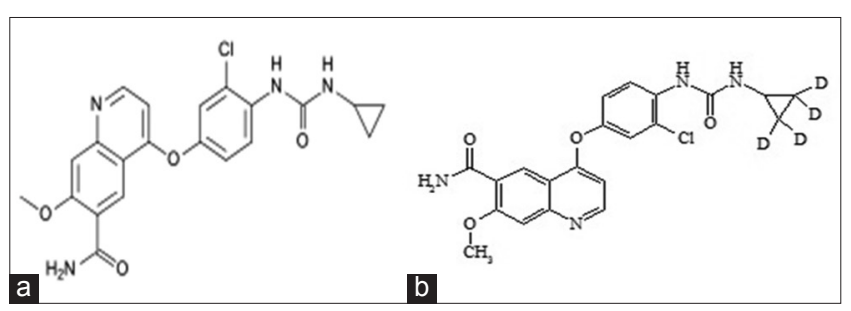

Fig. 1. Chemical structure of (a) lenvatinib (b) lenvatinib-D4

acid $(80: 20, v / v)$ and stored in the refrigerator at $2-8^{\circ} \mathrm{C}$ until analysis.

\section{Biological matrix}

Human plasma containing sodium heparin as an anticoagulant was used as a biological matrix during method validation. Selectivity and sensitivity tests were performed before bulk spiking.

\section{Sample preparation}

The LLE method was used to isolate LT and LTD4 from human plasma. For this purpose, $50 \mu \mathrm{L}$ of LTD $4(10 \mathrm{pg} / \mathrm{mL})$ and $200 \mu \mathrm{L}$ of plasma sample were added to the labeled polypropylene tubes and vortexed briefly for about 5 minutes. Thereafter, $50 \mu \mathrm{L}$ of $0.1 \mathrm{M}$ $\mathrm{NaOH}$ solution and $3 \mathrm{~mL}$ of extraction solvent (in the ratio of ethyl acetate: dichloromethane 80:20 [v/v]) were added and vortexed for about 10 minutes. Next, the samples were centrifuged at $4000 \mathrm{rpm}$ for approximately 5 minutes at ambient temperature. From each, a supernatant sample was transferred into labeled polypropylene tubes and evaporated to a dryness of $40^{\circ} \mathrm{C}$ briefly, and then reconstituted with a mobile phase solution (acetonitrile:0.1\% formic acid, 80:20,v/v), and the sample was transferred into autosampler vials and injected into the LC-MS for study.

\section{Method validation}

The validation was performed as per Food and Drug Administration guidelines to evaluate the method in terms of linearity response, sensitivity, selectivity, precision and accuracy (within-batch and between-batch/inter-day), stabilities (freeze-thaw, bench top, shortterm and long-term stock solutions, working solutions, and long-term stability in matrix), carryover effects, recovery, dilution integrity, matrix effect, matrix factor, autosampler re-injection reproducibility and ruggedness experiment $[10,16]$.

\section{System suitability}

System suitability experiment was performed by injecting six consecutive injections at least once in a day with using aqueous MQC solution. System performance experiment was performed by injecting a sequence of injections at the beginning of analytical batch and \% coefficient of variation $(\mathrm{CV})$ was calculated.

\section{Selectivity and sensitivity}

Selectivity was performed by analyzing human blank plasma samples from six different sources (donors) with an additional hemolyzed group and lipedimic group to test for interference at the retention times of analytes.

The sensitivity was compared with the LLOQ of the analyte with its blank plasma sample. The peak area of blank samples should not be $<20 \%$ of the mean peak area of the LOQ of LT and $5 \%$ of the mean peak area of LTD4.

\section{Calibration of standard curve (linearity and range)}

The linearity of the method was determined using standard plots associated with nine-point standard curve including LLOQ and an upper limit of quantification (ULOQ). Concentration of calibration curve standards was calculated against the calibration curve, and the linearity of the method was evaluated by ensuring the acceptance of precision and accuracy of calibration curve standards. Two consecutive calibration curve standards should not be beyond the acceptance criteria. The LLOQ was the lowest concentration at which the precision expressed by relative standard deviations (RSD, \%CV) is better than $20 \%$ and the accuracy (bias) expressed by a relative difference of the measured and true value was also $<20 \%$.

\section{Precision and accuracy}

The within-run and between-run percentage mean of precision and accuracy of the LT were measured by the percent coefficient using six replicate samples of variation over the concentration range of LLOQ, LQC, MQC, and HQC QC samples for the three precision and accuracy batches to their nominal values. The acceptable \% coefficient of precision and accuracy should be $<15 \%$. The between and within batch $\%$ mean precision and accuracy for $\mathrm{LQC}, \mathrm{MQC}$, and $\mathrm{HQC}$ samples were within the range of $85.00-115.00 \%$ and for the LLOQ within the range of $80.00-120.00 \%$, respectively.

\section{Recovery}

The $\%$ mean recoveries were determined by comparing the mean peak area of the six replicates of extracted plasma QC samples at high, middle 1 and 2 and low concentrations against respective mean peak area of the six replicates of un-extracted QC samples at high, middle, and low concentrations.

A recovery of more than $50 \%$ was considered adequate to obtain required sensitivity. The \% mean IS recovery was determined by comparing the mean peak area of IS in the extracted plasma QC samples at MQC concentration against the mean peak area of IS in the unextracted QC samples at MQC concentration.

\section{Dilution integrity}

The dilution integrity of the method was evaluated by diluting the stock solution prepared as spiked QC sample at concentration 1.5-2 times above the concentration of the highest standard in the calibration curve in the screened biological matrix. Conduct dilution integrity experiment using six replicates each of diluted QC $(1 / 2)$ and diluted QC $(1 / 10)$ samples. Process and analyze the diluted QC samples along with freshly spiked calibration curve standards and at least two sets of batch qualifying QCs (at lower and higher).

\section{Ruggedness}

Ruggedness of the method was evaluated using different analyst and different column of the same make and model or different equipment of the same make and model. The ruggedness experiment should meet the acceptance criteria for linearity and intra-batch accuracy and precision.

\section{Matrix effect}

To predict the variability of matrix effects in samples from individual subjects, matrix effect was quantified by determining the matrix factor, which was calculated as follows:

Matrix factor $=\frac{\begin{array}{l}\text { Peak response ratio in presence of extracted matrix } \\ \text { (post extracted })\end{array}}{\text { Peak response ratio in aqueous standards }}$

Six lots of blank biological matrices were extracted each in triplicates and post spiked with the aqueous standard at the mid-QC level, and compared with aqueous standards of the same concentration. The overall precision of the matrix factor is expressed as $\% \mathrm{CV}$ and it should be $<15 \%$.

\section{Stability of LT and LTD4}

Short-term stock solution stability

Short-term stock solution stability for LT and IS was performed at the stock concentration using six consecutive injections of aqueous standard equivalent to ULOQ concentration and working concentration, respectively, after storage of at least $6 \mathrm{hrs}$ at ambient temperature. Stability was assessed by comparing the stock dilutions of LT and IS 
prepared from the freshly prepared stock solutions (comparison) against stock dilutions of IS prepared from the stock solutions stored at ambient temperature (stability). Short-term stock solution stability was evaluated by comparing the mean response of stability samples against mean response of comparison samples. The precision and accuracy for the stability samples must be within $\leq 15$ and $\pm 15 \%$, respectively, of their nominal concentrations.

\section{Long-term stock solution stability}

Long-term stock solution stability for LT and LTD4 (IS) was performed at the stock concentration using six consecutive injections of aqueous standard equivalent to ULOQ concentration and working concentration, respectively, after storage of at least 4 days in the refrigerator at $2-8^{\circ} \mathrm{C}$. Stability was assessed by comparing the stock dilutions of LT and LTD4 (IS) prepared from the freshly prepared stock solutions (comparison) against stock dilutions of LT and LTD4 (IS) prepared from the stock solutions stored at $2-8^{\circ} \mathrm{C}$ (stability). Long-term stock solution stability was evaluated by comparing the mean response of stability samples against mean response ratios of comparison samples.

\section{Working solution stability}

Short-term stability (at least $6 \mathrm{hrs}$ at ambient temperature) and longterm stability (at least 4 days at $2-8^{\circ} \mathrm{C}$ ) for working solutions of drug (stock solution ULOQ and LLOQ) and IS were performed using six consecutive injections of equivalent aqueous standards prepared from fresh and stored solutions.

Short-term stability and long-term stability of working solution were evaluated by comparing the mean response of stability samples against mean response of comparison samples.

\section{Stability of drug in biological matrix}

Perform the matrix stability experiment using freshly prepared calibration curve standard and three replicates of freshly prepared batch qualifying QC samples at HQC and LQC levels. The precision and accuracy for the stability samples must be within $\leq 15$ and $\pm 15 \%$, respectively, of their nominal concentrations. Stability studies in biological matrix were conducted in the various conditions at LQC and HQC levels as described below:

\section{Freeze-thaw stability}

Freeze-thaw stability of the spiked QC samples was determined after first and third freeze-thaw cycles stored at $-20 \pm 5^{\circ} \mathrm{C}$. Six replicates of each HQC, and LQC samples were used for assessing each freezethaw experiment (for first and third cycle at both the freezing temperatures). The first freeze-thaw cycle was of at least $24 \mathrm{hrs}$ followed by a minimum of 12 hrs for subsequent cycles. Process and analyze freeze-thaw stability samples along with freshly spiked calibration curve and comparison samples (six replicates of each LQC and $\mathrm{HQC}$ ) in screened biological matrix. Evaluate the freeze-thaw stability on the basis of \% change of LQC and HQC samples. The \% accuracy and \% CV of LQC and HQC should be within \pm 15.00 and $\leq 15.00$, respectively.

\section{Bench top stability}

Spiked QC samples (six replicates of each LQC and HQC) were stored in a deep freezer at temperature $-20 \pm 5^{\circ} \mathrm{C}$, which was retrieved after minimum $12 \mathrm{hrs}$ of freezing and was kept at ambient temperature on working bench for recommended period of at least $24 \mathrm{hrs}$. Six replicates of each HQC and LQC samples were used for assessing the bench top stability experiment. On the completion of recommended period, process and analyze bench top stability samples along with freshly spiked calibration curve and comparison samples (six replicates of each LQC and HQC) in screened biological matrix.

Evaluate the bench top stability on the basis of \% accuracy and \% CV of LQC and HQC samples.

\section{Autosampler re-injection reproducibility}

Autosampler re-injection reproducibility was evaluated by re-injecting accepted precision and accuracy batch, which were stored preferably in either autosampler or in refrigerator for at least $55 \mathrm{hrs}$ or as per requirement. Autosampler re-injection reproducibility was evaluated by $\%$ accuracy and $\%$ CV of LQC and HQC samples.

\section{Long-term stability in biological matrix}

The long-term stability samples of LQC, MQC, and HQC samples were kept frozen in vials at $-20 \pm 5^{\circ} \mathrm{C}$ for 40 days were assessed along with freshly processed calibration and comparison samples (six samples each of LQC, MQC, and HQC). The initial bacterial endotoxins test concentration freshly after sample treatment preparation was assumed to be $100 \%$. The selection of the stability duration on the basis of the characteristic of the analyte(s)

\section{RESULTS AND DISCUSSIONS}

\section{Method development}

LC-MS/MS has been used as one of the most powerful analytical tools in clinical pharmacokinetics for its selectivity, sensitivity, and reproducibility. The goal of this work is to develop and validate a simple, sensitive, rapid, rugged, and reproducible assay method for the quantitative determination of LT from human plasma samples.

Chromatographic conditions, especially the composition and nature of the mobile phase, usage of different columns, different extraction methods such as solid phase, precipitation, and liquid-liquid extraction methods were optimized through several trials to achieve the best resolution and increase the signal of LT and LTD4. The MS optimization was performed by direct infusion of solutions of both LT and LTD4 into the ESI source of the MS. The critical parameters in the ESI source include the needle (ESI) voltage, capillary voltage, source temperature, and other parameters such as nebulizer gas, heater gas, and desolvation gases were optimized to obtain a better spray shape, resulting in better ionization of the protonated ionic LT and LTD4 molecules. Product ion spectrum for LT and LTD4 yielded highabundance fragment ions of $\mathrm{m} / \mathrm{z} 370.10$ and $\mathrm{m} / \mathrm{z} 370.10$, respectively (Figs. 2 and 3). After MS parameters optimized, chromatographic conditions such as mobile phase optimization, column optimization, and extraction method optimization were performed to obtain a fast and selective LC method. A good separation and elution were achieved using acetonitrile: $0.1 \%$ formic acid $(80: 20, \mathrm{v} / \mathrm{v})$ as the mobile phase, at a flow-rate of $0.6 \mathrm{~mL} /$ minutes, and injection volume of $10 \mu \mathrm{L}$. Zorbax Eclipse XDB-C18 $(150 \times 4.6 \mathrm{~mm}, 5 \mu)$ column and liquid-liquid extraction method were optimized for the best chromatography (Fig. 4).

\section{Method validation $[17,18]$}

\section{System suitability}

System performance experiment was performed by injecting six consecutive injections at the beginning of the analytical batch. $\% \mathrm{CV}$ was 3.52 .

\section{Carryover test}

For carryover test, two samples of the upper LOQ (ULOQ) and four samples of blank plasma were processed. These samples were injected in the following sequence.

a. 2 blank samples

b. 2 ULOQ samples

c. 2 blank samples.

The step (b) and (c) were repeated 2 times. The results demonstrate that there was no interference from the previous injection.

\section{Selectivity and specificity}

The analysis of LT and LTD4 using multiple reaction monitoring function was highly selective with no interfering compound. 


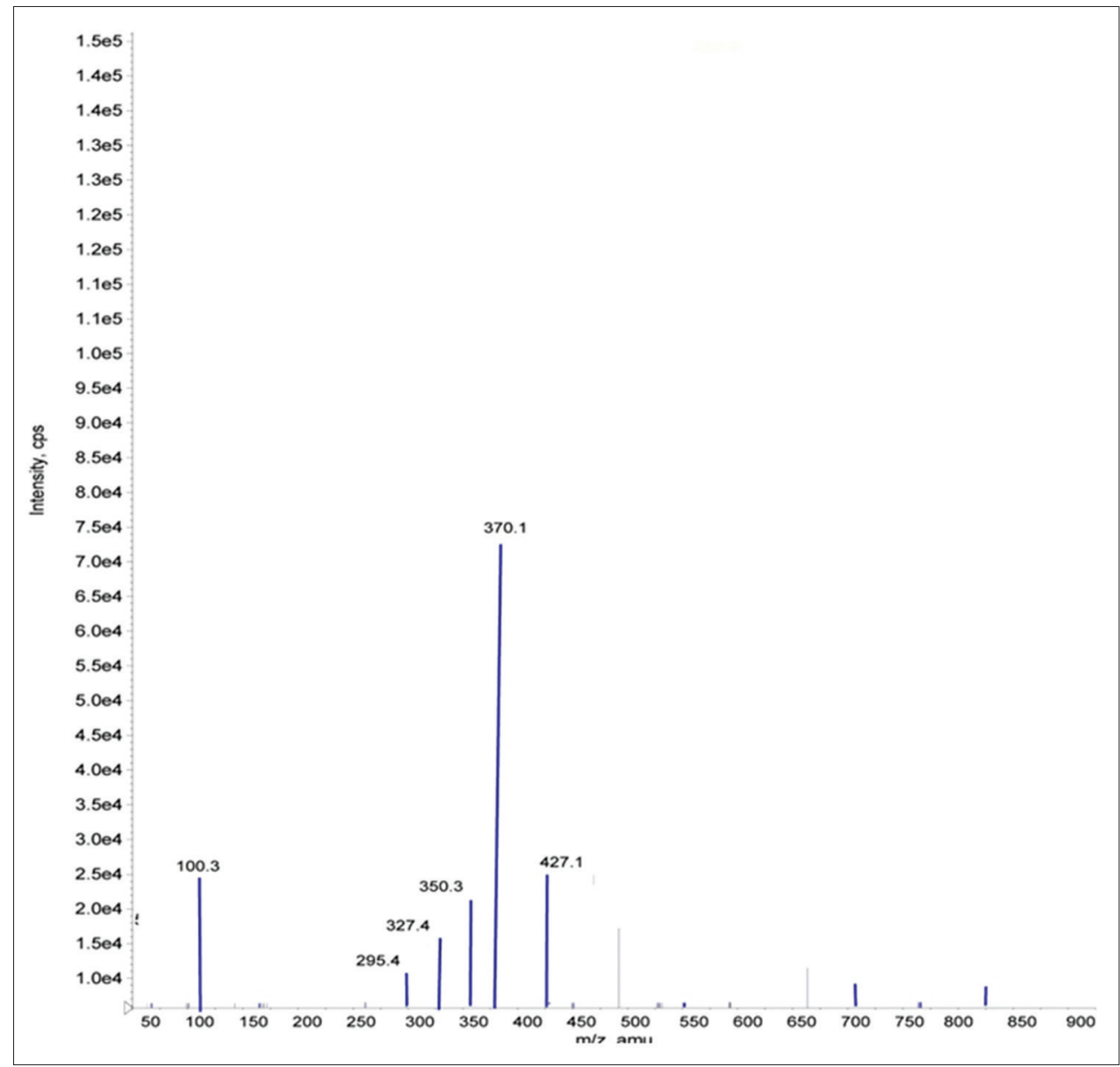

Fig. 2: Mass fragmentation pattern of lenvatinib

Table 1: Calibration curve

\begin{tabular}{llll}
\hline $\begin{array}{l}\text { Spiked plasma } \\
\text { concentration } \\
\text { (pg/ml) }\end{array}$ & $\begin{array}{l}\text { Concentration } \\
\text { measured } \\
\text { (pg/ml) }\end{array}$ & \% CV (n=5) & \% accuracy \\
\hline 10.20 & $8.651 \pm 2.1$ & 1.1 & 86.506 \\
20.10 & $17.099 \pm 7.5$ & 2.6 & 85.072 \\
35.10 & $34.109 \pm 0.9$ & 1.7 & 97.177 \\
70.23 & $69.937 \pm 1$ & 1.5 & 99.625 \\
100.32 & $102.283 \pm 2.7$ & 2.8 & 101.921 \\
200.60 & $204.666 \pm 1.9$ & 3.6 & 102.093 \\
301.20 & $304.057 \pm 0.7$ & 3.2 & 101.015 \\
401.31 & $401.807 \pm 0.4$ & 3.2 & 100.126 \\
501.61 & $497.59 \pm 1.4$ & 2.7 & 99.201 \\
\hline
\end{tabular}

Values are expressed as (mean \pm SD) $(n=6)$. SD: Standard deviation, $\mathrm{CV}$ : Coefficient of variation

Chromatograms obtained from plasma spiked with LT $(10.2 \mathrm{pg} / \mathrm{mL})$ and LTD4 $(100 \mathrm{pg} / \mathrm{mL})$.

\section{Limit of detection (LOD) and LOQ}

The limit of detection was used to determine the instrument detection levels for LT even at low concentrations. $5 \mu \mathrm{L}$ of a $0.5 \mathrm{pg} / \mathrm{mL}$ solution was injected and estimated LOD was $2.5 \mathrm{pg} / \mathrm{ml}$ with $\mathrm{S} / \mathrm{N}$ values $\geq 3-5$. The LOQ for this method was proved as the lowest concentration of the calibration curve which was proved as $0.5 \mathrm{pg} / \mathrm{ml}$.

\section{Calibration curve standards, precision, and accuracy}

Calibration curves were plotted as the peak area ratio (LT/LTD4) versus (LT) concentration. Calibration was found to be linear over the concentration range of $10.2-501.60 \mathrm{pg} / \mathrm{mL}$. The $\mathrm{CV} \%$ was $<5 \%$ and the accuracy ranged from $85 \%$ to $102 \%$. The determination coefficients $\left(\mathrm{r}^{2}\right)$ were $>0.9995$ for all curves (Table 1). As shown in Table 2, the intra-batch CV\% was $<5 \%$ and the accuracy ranged from $98 \%$ to $101.0 \%$. The inter-batch CV\% was $<5 \%$ and the accuracy ranged from $98.0 \%$ to $101.3 \%$. These results indicate the adequate reliability and reproducibility of this method within the analytical range.

\section{Recovery}

The recovery following the sample preparation using liquid-liquid extraction with methyl tertiary butyl ether was calculated by comparing the peak area of LT in plasma samples with the peak area of solvent samples and was estimated at control levels of LT. The recovery of LT was determined at three different concentrations 30.1, 250.10, and $461.10 \mathrm{pg} / \mathrm{mL}$, was found as $83.81,93.08$, and $94.53 \%$, respectively (Table 3). The overall average recovery of LT and LTD4 was found to be 90.48 and $85.51 \%$, respectively.

\section{Matrix effect}

Six lots of blank biological matrices were extracted each in triplicates and post spiked with the aqueous standard at the mid-QC level, and compared with neat standards of same concentration in alternate injections. The overall precision of the matrix factor is 10.13 for LT. There was no ion suppression and ion enhancement effect observed due to IS and analyte at respective retention time.

\section{Short-term stock solution stability}

\section{Short-term stock solution stability at room temperature}

Stock solution each of LT and IS was stable after approximately $9 \mathrm{hrs}$ and 30 minutes at room temperature. For LT and LTD4 (IS) the \% accuracy was 100.21 and 101.00 , respectively. 


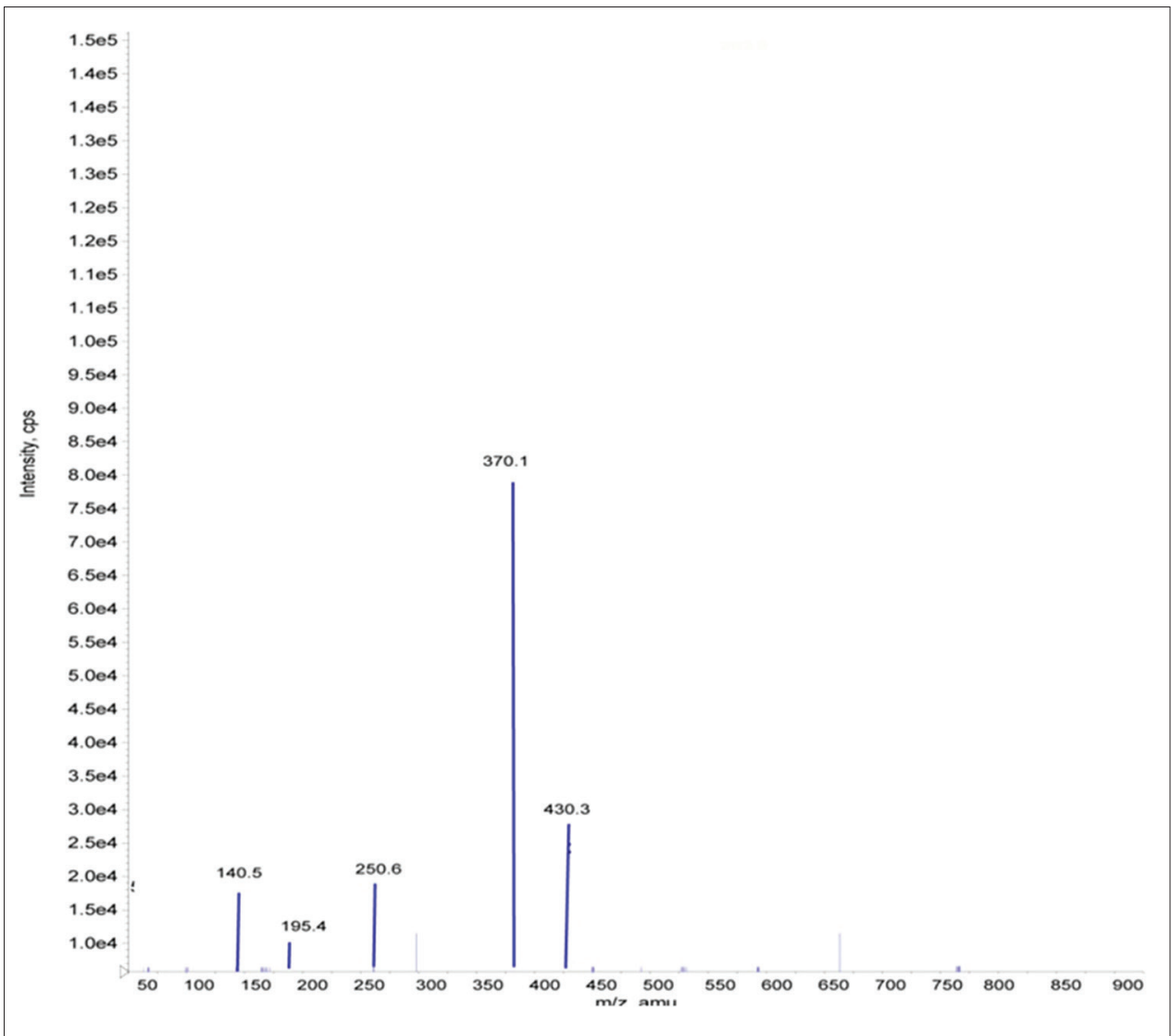

Fig. 3: Mass fragmentation pattern of lenvatinib-D4

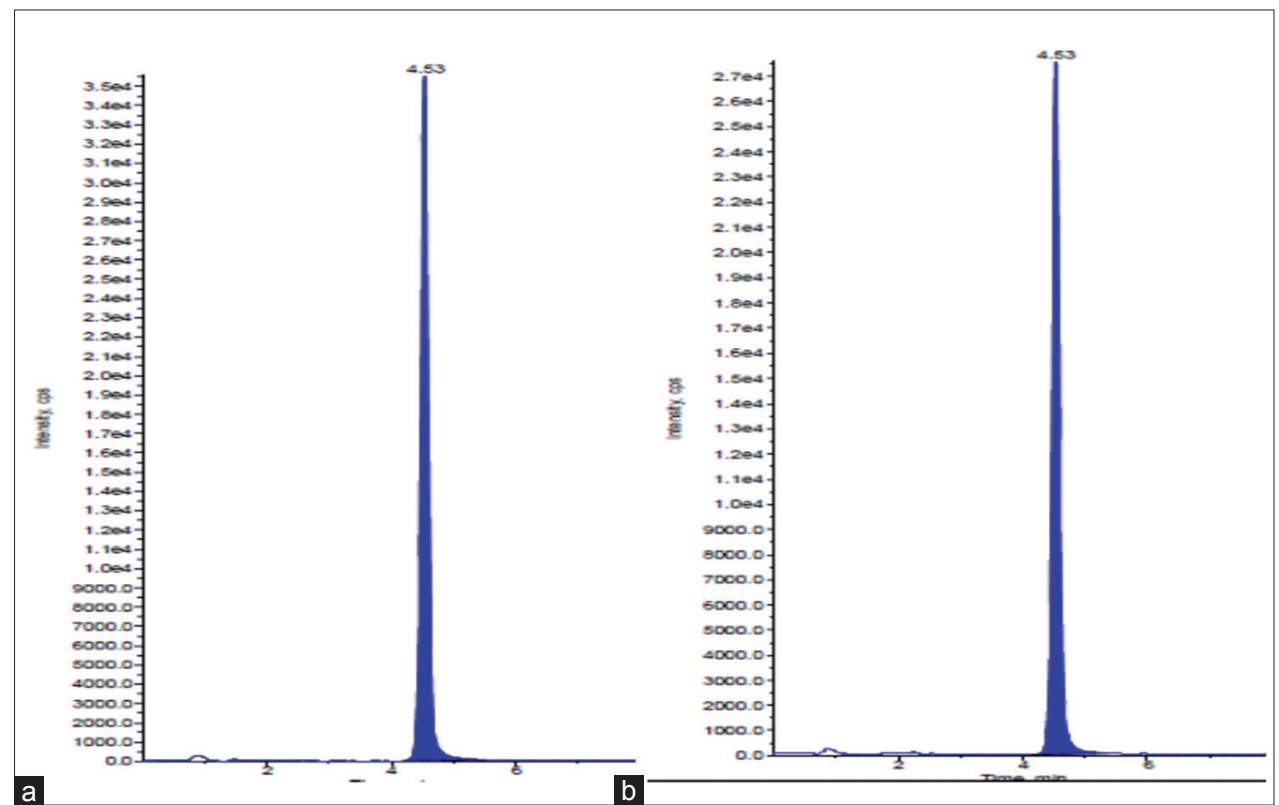

Fig. 4: Representative chromatograms in plasma sample (a) chromatogram of lenvatinib (b) chromatogram of lenvatinib-D4

\section{Short-term stock solution stability at refrigerator $\left(2-8^{\circ} \mathrm{C}\right)$}

Stock solution each of LT and IS was stable after approximately 9 hrs and 30 minutes at refrigerated temperature $2-8^{\circ} \mathrm{C}$. For LTD4 (IS) the $\%$ accuracy was 101.00

\section{Stability (freeze-thaw, autosampler, bench top, long term)}

Quantification of the LT in plasma subjected to three freeze-thaw $\left(-30^{\circ} \mathrm{C}\right.$ to room temperature) cycles shows the stability of the analyte.
The $\%$ accuracy ranged from $100.58 \%$ to $105.42 \%$ of the theoretical values. No significant degradation of the LT was observed even after $55 \mathrm{hrs}$ storage period in the autosampler tray, and the \% accuracy ranged from $100.96 \%$ to $104.77 \%$ of the theoretical values. No significant degradation of the LT was observed even after 24 hrs storage period in the room temperature, and the \% accuracy ranged from $100.81 \%$ to $100.91 \%$ of the theoretical values. In addition, the long-term stability of LT in QC samples after 40 days of storage at $-20^{\circ} \mathrm{C}$ was also evaluated. 
Table 2: Precision and accuracy

\begin{tabular}{|c|c|c|c|c|c|c|}
\hline \multirow{2}{*}{$\begin{array}{l}\text { Spiked plasma } \\
\text { concentration }(\mathrm{pg} / \mathrm{ml})\end{array}$} & \multicolumn{3}{|c|}{ Within-run (intra-day) } & \multicolumn{3}{|c|}{ Between-run (inter-day) } \\
\hline & $\begin{array}{l}\text { Concentration } \\
\text { measured }(\mathrm{pg} / \mathrm{ml})\end{array}$ & $\% \mathrm{CV}$ & $\%$ Accuracy & $\begin{array}{l}\text { Concentration } \\
\text { measured }(\mathrm{pg} / \mathrm{ml})\end{array}$ & $\% \mathrm{CV}$ & $\%$ Accuracy \\
\hline 30.10 & 28.91 & 2.42 & 95.64 & 29.32 & 0.55 & 97.16 \\
\hline 250.10 & 248.54 & 1.06 & 98.09 & 249.12 & 0.03 & 99.62 \\
\hline 461.60 & 462.97 & 1.28 & 100.08 & 461.60 & 0.28 & 100.07 \\
\hline
\end{tabular}

Values are expressed as (mean \pm SD) $(n=6)$. SD: Standard deviation, CV: Coefficient of variation

Table 3: Recovery of spiked plasma

\begin{tabular}{lll}
\hline Spiked concentration of LT $(\mathbf{p g} / \mathbf{m L})$ & \multicolumn{1}{l}{ Peak height ratio (mean \pm SD), $\mathbf{n = 6}$} & \multicolumn{2}{c}{ \% Recovery } \\
\cline { 2 - 3 } & \multicolumn{1}{c}{ Extracted LT response (pg/ml) } & Un-extracted LT response (pg/ml) \\
\hline HQC (461.60) & $153564.20 \pm 2359.76$ & $162475.42 \pm 2809.32$ \\
MQC (250.10) & $61337.14 \pm 849.27$ & $65899.19 \pm 889.45$ \\
LQC (30.10) & $4024.14 \pm 251.46$ & $4788.19 \pm 253.35$ \\
\hline
\end{tabular}

Values are expressed as (mean \pm SD) (n=6). SD: Standard deviation, LT: Lenvatinib, HQC: High-quality control, MQC: Middle-quality control, LQC: Lower quality control

Table 4: Stability studies

\begin{tabular}{|c|c|c|c|c|c|c|c|c|}
\hline \multirow{3}{*}{$\begin{array}{l}\text { Spiked plasma } \\
\text { concentration } \\
(\mathrm{pg} / \mathrm{ml})\end{array}$} & \multirow{2}{*}{\multicolumn{2}{|c|}{$\begin{array}{l}\text { Room temperature } \\
\text { stability }\end{array}$}} & \multirow{2}{*}{\multicolumn{2}{|c|}{$\begin{array}{l}\text { Autosampler stability } \\
55 \text { hrs }\end{array}$}} & \multirow{2}{*}{\multicolumn{2}{|c|}{$\begin{array}{l}\text { Long-term stability } \\
40 \text { days }\end{array}$}} & \multirow{2}{*}{\multicolumn{2}{|c|}{$\begin{array}{l}\text { Freeze and thaw stability } \\
\text { Cycle (48 hrs) }\end{array}$}} \\
\hline & & & & & & & & \\
\hline & $\begin{array}{l}\text { Concentration } \\
\text { measured } \\
(\mathrm{pg} / \mathrm{ml})\end{array}$ & $\begin{array}{l}\% C V \\
(n=6)\end{array}$ & $\begin{array}{l}\text { Concentration } \\
\text { measured } \\
(\mathrm{pg} / \mathrm{ml})\end{array}$ & $\begin{array}{l}\% C V \\
(n=6)\end{array}$ & $\begin{array}{l}\text { Concentration } \\
\text { measured } \\
(\mathrm{pg} / \mathrm{ml})\end{array}$ & $\begin{array}{l}\% C V \\
(n=6)\end{array}$ & $\begin{array}{l}\text { Concentration } \\
\text { measured } \\
(\mathrm{pg} / \mathrm{ml})\end{array}$ & $\begin{array}{l}\% C V \\
(n=6)\end{array}$ \\
\hline 30.10 & $31.21 \pm 0.11$ & 1.3 & $29.87 \pm 1.10$ & 1.3 & $31.08 \pm 1.04$ & 0.8 & $31.49 \pm 1.12$ & 1.77 \\
\hline 461.70 & $460.98 \pm 0.41$ & 0.9 & $460.41 \pm 1.33$ & 0.93 & $461.44 \pm 0.12$ & 0.4 & $462.22 \pm 2.05$ & 0.7 \\
\hline
\end{tabular}

Values are expressed as (mean \pm SD) $(n=6)$. SD: Standard deviation, $\mathrm{CV}$ : Coefficient of variation

The concentrations ranged from $99.67 \%$ to $100.56 \%$ of the theoretical values. These results confirmed the stability of LT in human plasma for at least 40 days at $-20^{\circ} \mathrm{C}$ (Table 4 ).

\section{CONCLUSION}

The LC-MS/MS validated method has proved to be very simple, sensitive and reliable and successfully applied for the pharmacokinetic study in human plasma. The assay method is specific due to the inherent selectivity of tandem MS. The major advantage of this method is the use of deuterated LTD 4 as an IS. The run time is within 8 minutes, and only $0.200 \mathrm{~mL}$ of plasma was required for each determination of LT, and thus the stress to volunteers or patients in clinical studies were greatly reduced. This method is suitable and convenient to pharmacokinetics and bioavailability studies for estimation of LT in biological samples by LC-MS/MS

\section{ACKNOWLEDGMENTS}

Authors wish to thank the support received from IICT (Indian institute of chemical technology) Hyderabad, India, for providing Literature survey. APL Research Centre Pvt. Ltd Hyderabad, India, to carry out this research work.

\section{REFERENCES}

1. Schlumberger M, Tahara M, Wirth LJ, Robinson B, Brose MS, Elisei R, et al. Lenvatinib versus placebo in radioiodine-refractory thyroid cancer. N Engl J Med 2015;372(7):621-30.

2. Cabanillas ME, Schlumberger M, Jarzab B, Martins RG, Pacini F, Robinson B, et al. A phase 2 trial of lenvatinib (E7080) in advanced, progressive, radioiodine-refractory, differentiated thyroid cancer: A clinical outcomes and biomarker assessment. Cancer 2015;121(16):2749-56.

3. Krajewska J, Kukulska A, Jarzab B. Drug safety evaluation of lenvatinib for thyroid cancer. Expert Opin Drug Saf 2015;14(12):1935-43.
4. Cabanillas ME, Habra MA. Lenvatinib: Role in thyroid cancer and other solid tumors. Cancer Treat Rev 2016:42:47-55.

5. Nair A, Lemery SJ, Yang J, Marathe A, Zhao L, Zhao H, et al. FDA approval summary: Lenvatinib for progressive, radio-iodine-refractory differentiated thyroid cancer. Clin Cancer Res 2015;21(23):5205-8.

6. Yeung KT, Cohen EE. Lenvatinib in advanced, radioactive iodinerefractory, differentiated thyroid carcinoma. Clin Cancer Res 2015;21(24):5420-6

7. Costa R, Carneiro BA, Chandra S, Pai SG, Chae YK, Kaplan JB, et al. Spotlight on lenvatinib in the treatment of thyroid cancer: Patient selection and perspectives. Drug Des Devel Ther 2016;10:873-84.

8. Cserhati T, Szogyi M. Chromatography of anticancer drugs. Eur Chem Bull 2013;2(10):715-21

9. Prashanthi Y, Ahmed MA, Vijaya K, Riyazuddin. Method development and validation of lenvatinib drug by RP-HPLC in pharmaceutical drug dosage form. Indo Am J Pharm Sci 2016;3(10):1078-85.

10. Mano Y, Kusano K. A validated LC-MS/MS method of total and unbound lenvatinib quantification in human serum for protein binding studies by equilibrium dialysis. J Pharm Biomed Anal 2015;114:82-7.

11. Dubbelman AC, Rosing H, Thijssen B, Gebretensae A, Lucas L, Chen $\mathrm{H}$, et al. Development and validation of LC-MS/MS assays for the quantification of E7080 and metabolites in various human biological matrices. J Chromatogr B Analyt Technol Biomed Life Sci 2012;887$888: 25-34$

12. Dubbelman AC, Rosing H, Nijenhuis C, Huitema AD, MerguiRoelvink M, Gupta A, et al. Pharmacokinetics and excretion of (14) C-lenvatinib in patients with advanced solid tumors or lymphomas. Invest New Drugs 2015;33:233-40.

13. Shumaker RC, Aluri J, Fan J, Martinez G, Thompson GA, Ren M. Effect of rifampicin on the pharmacokinetics of lenvatinib in healthy adults. Clin Drug Investig 2014;34(19):651-9.

14. Shumaker R, Aluri J, Fan J, Martinez G, Pentikis H, Ren M. Influence of hepatic impairment on lenvatinib pharmacokinetics following singledose oral administration. J Clin Pharmacol 2015;55(3):317-27.

15. Okamoto K, Kodama K, Takase K, Sugi NH, Yamamoto Y, Iwata M, et al. Antitumor activities of the targeted multi-tyrosine kinase inhibitor lenvatinib (E7080) against RET gene fusion-driven tumor models. 
Cancer Lett 2013;340(1):97-103

16. Department of Health and Human Services. Guidance for Industry. Bio-Analytical Method Validation. Rockville, MD: U.S. Department of Health and Human Services, Food and Drug Administration, Center for Drug Evaluation and Research (CDER), Center for Biologics Evaluation and Research (CBER); 2001.
17. Singhal P, Shah PA, Shah JV, Sanyal M, Shrivastav PS. Sensitive and rapid estimation of lapatinib, an anticancer drug in spiked human plasma by LC-MS/MS. Int J Pharm Pharm Sci 2016;8(1):214-20.

18. Singhal P, Shah PA, Shah JV, Sharma P, Shrivastav PS. Determination of capecitabine-an anticancer drug in dried blood spot by LC-ESI-MS/MS. Int J Pharm Pharm Sci 2015;7(12):238-45. 